Rhoda Mae V. Boncalon, MD Marida Arend V. Arugay, MD Rachel Zita H. Ramos, MD

Department of OtorhinolaryngologyHead \& Neck Surgery

Western Visayas Medical Center
Correspondence: Rhoda Mae V. Boncalon, MD Department of ENT-HNS

Western Visayas Medical Center

Q. Abeto St, Mandurriao, Iloilo City 5000

Philippines

Phone: +639177222407

Fax: (6333) 3211797

Email: docboink@yahoo.com

Reprints will not be available from the author.

Funding support for this study was received from the Research Committee of the Western Visayas Medical Center. The authors signed a disclosure that they have no proprietary or financial interest in any organization that may have a direct interest in the subject matter of this manuscript, or in any product used or cited in this study.

Presented at the Western Visayas Medical Center 1st Interdepartmental Residents' Research Contest (1st Place), WVMC Supply Building, Rooftop, Mandurriao, Iloilo City, November 26, 2007; Analytical Research Contest (3rd Place), Philippine Society of Otolaryngology - Head and Neck Surgery, December 1, 2007 at Romblon Room, Sofitel Philippine Plaza Manila, Pasay City, December 1, 2007;

International Research Conference (West Visayas State University) Amigo Terrace Hotel, lloilo City, February 29, 2008.

\section{A Preliminary Study on the Efficacy of Plumeria acuminata (Kalachuchi) Bark Extract Ointment Versus Clotrimazole Cream in the Treatment of Otomycosis}

\section{ABSTRACT}

Objective: To compare the therapeutic efficacy of kalachuchi (Plumeria acuminata Ait.) bark extract ointment (KO) and clotrimazole cream $1 \%(\mathrm{CC})$ in the treatment of otomycosis.

\section{Methods}

Design: Randomized double blind controlled trial

Setting: Outpatient otorhinolaryngology clinic of a tertiary government hospital

Subjects: Patients aged 18-years-old and above diagnosed clinically to have otomycosis with a positive potassium hydroxide $(\mathrm{KOH})$ smear were randomly assigned to kalachuchi (Plumeria acuminata Ait.) bark extract ointment or clotrimazole cream $1 \%$ in unlabeled containers. Selfapplication thrice daily for two weeks followed initial detailed instructions and demonstration. Symptoms, physical findings and repeat $\mathrm{KOH}$ smears were recorded after the first and second weeks of treatment.

Results: Eighteen patients with otomycosis were enrolled in the study. There was one dropout per treatment group with no intention to treat. There were no statistically significant differences between $\mathrm{KO}$ and CC, with $75 \%(\mathrm{n}=8)$ and $87.5 \%(\mathrm{n}=8)$ cure rates, respectively. One subject in the $\mathrm{KO}$ arm reported severe ear pain.

Conclusion: Kalachuchi extract ointment may be a promising topical antifungal agent. Multicenter clinical trials to establish its efficacy and safety as an effective alternative in the management of otomycosis should be conducted.

Key words: Otomycosis, kalachuchi, Plumeria acuminata Ait., clotrimazole, clinical trial, herbal medicine 


\section{ORIGINAL ARTICLES}

Philippine Journal Of Otolaryngology-Head And Neck Surgery

VOL. 24 NO. 1 JANUARY - JUNE 2009

PJOHLS

Otomycosis is one of the common otologic conditions requiring medical consult and therapy. Most otomycosis isolates include Aspergillus or Candida spp., ${ }^{1,2}$ Clinical presentation may include intractable itching of the external auditory canal, otalgia, tinnitus and ear discharge. ${ }^{3,4}$ Physical examination reveals an erythematous canal with black, gray or white fungal elements (Figure 1). Direct microscopy using $10 \% \mathrm{KOH}$ confirms the diagnosis. ${ }^{5}$ Treatment often requires mechanical cleansing and 1-2 weeks application of topical antifungal agents. ${ }^{6,7}$ Clotrimazole $1 \%$ cream is commonly prescribed, providing symptom relief within 2 weeks in $96 \%$ of patients. ${ }^{8}$ Other antifungal drops or powder medications (clotrimazole and nystatin) are also effective in many cases..$^{910}$

Of the 10 locally available medicinal plants in the priority list of the Philippine Council for Health Research and Development (PCHRD) of the Department of Science and Technology (DOST) and Plant Resource of South East Asia (PROSEA), kalachuchi \{Plumeria acuminata Ait.) has one of the highest activities in assays against Candida species. Antimycotic properties of kalachuchi (Plumeria acuminata Ait.) bark extract against Aspergillus flavus and Aspergillus niger have been shown in in-vitro studies. ${ }^{12}$ Application of this extract in controlled and limited number of subjects may help establish its pharmacotherapeutic potentials.

The objective of this study was to compare the therapeutic efficacy of kalachuchi (Plumeria acuminata Ait.) bark extract ointment (KO) and the standard clotrimazole cream $1 \%$ (CC) in the treatment of otomycosis.

\section{METHODS}

Design: Randomized double blind controlled trial. The study was reviewed and approved by the ethics committee of the Western Visayas Medical Center.

Setting: Outpatient otorhinolaryngology clinic in a tertiary private hospital.

Subjects: Voluntary, informed consent was obtained from 18 patients aged 18 to 70 years with otomycosis defined as presence of itchiness, ear pain, ear discharge, ear fullness or hearing impairment with otoscopic findings of external auditory canal erythema, discharge and fungal elements, testing positive on $\mathrm{KOH}$ smear were included in the study. Ten percent $\mathrm{KOH}$ smears were performed on swabs taken from the affected ear canal. In cases of bilateral otomycosis, the right ear was chosen for evaluation. Exclusion criteria were use of any topical otic medication and/or oral antifungal medication the past 30 days, presence of tympanic membrane perforation, concomitant otitis media, previous surgery on the test ear, history of hypersensitivity to clotrimazole and pregnant or lactating patients.

Intervention: Following thorough mechanical ear cleansing, patients were randomly assigned to the use of unlabeled containers of either clotrimazole cream $1 \%$ in group A or kalachuchi (Plumeria acuminata Ait.) bark extract ointment in group B. Details of kalachuchi bark extract preparation followed those previously described ${ }^{12}$ and are

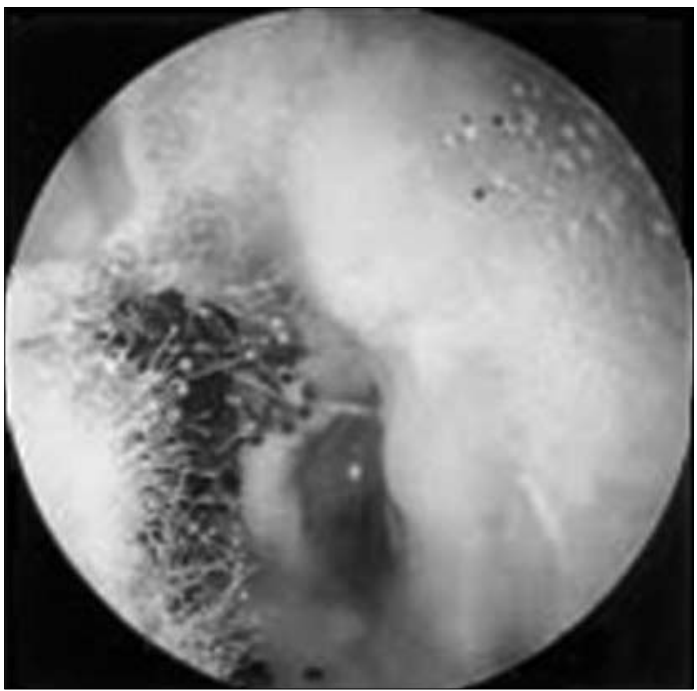

Figure 1. Otoscopy revealing black \& white fungal elements

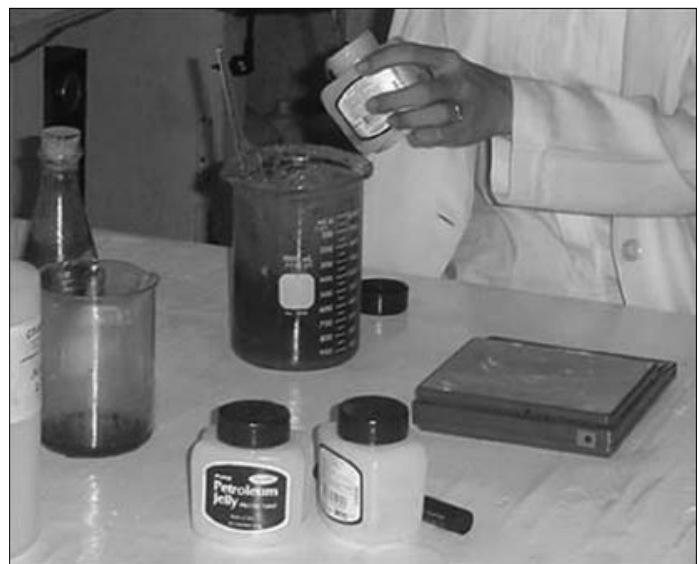

Figure 2. Preparation of kalachuchi (Plumeria acuminata Ait.) ointment

available through corresponding author (Figure 2). A voucher specimen of the said kalachuchi was sent to a taxonomist and was positively identified as Plumeria acuminata Ait.

After detailed instructions and demonstration, the topical agent was self-applied $3 \mathrm{x}$ a day for two weeks. Adverse events were monitored during the two-week treatment period. Patients with localized adverse effects such as hypersensitivity reactions, aural tenderness, formation of eczematous lesions and perichondritis were instructed to discontinue the test drug. Rescue drugs (antihistamines, analgesics or oral antibiotics) were administered to one such patient until events resolved. Patients who developed adverse effects, those with poor compliance to the assigned medication (use of $<50 \%$ of the test drug) and those who did not wish to continue the treatment were further excluded from the study. 
ORIGINAL ARTICLES

Outcome Measures and Statistical Analysis: Clinical symptoms, physical examination findings and $\mathrm{KOH}$ smear results were recorded before treatment and at Day 7 and Day 14 of treatment. Comparison between two proportions testing for significant difference was performed using the z-test and chi square test.

\section{RESULTS}

Eighteen patients diagnosed clinically and microbiologically to have otomycosis were initially enrolled in the study comprising 9 test ears in each treatment group. Dropouts included one subject lost to follow up under CC treatment and one subject experiencing severe aural pain and tenderness under KO treatment. Sixteen patients with 8 patients in each treatment arm remained for analysis. These were 7 males and 9 females with a mean average age of 44 years.

The most common presentation of the patients upon consult was ear fullness (75\%) and hearing impairment (75\%) followed by itchiness of the affected ear (62.5\%). On otoscopic examination, all patients had hyphal elements in the test ear. Fifty percent had ear canal erythema and only $34 \%$ had ear discharge. There was no significant difference between baseline characteristics of the two groups (Table 1).

After 7 days of treatment, $37.5 \%$ of the subjects using CC and $25 \%$ of the subjects using $\mathrm{KO}$ reported symptom resolution. After two weeks, both groups had an equal incidence of patients (62.5\%) who did not report any residual symptoms (Table 2).

After one week of therapy, otoscopic examination revealed normal findings in $62.5 \%$ and $32.5 \%$ of subjects of the CC and KO groups, respectively. There was no statistically significant difference between the two treatment arms after 7 and 14 days of therapy (Table 2). It must be noted that in this study, the $62.5 \%$ response rate to the standard treatment $\mathrm{CC}$ requires a $0 \%$ response scenario to $\mathrm{KO}$ in order to establish a statistically significant difference.

After a week of treatment, only one patient (12.5\%) in the KO group had a negative $\mathrm{KOH}$ smear while $50 \%$ of the $\mathrm{CC}$ group already showed absence of fungal elements. After two weeks of therapy, $75 \%$ and $87.5 \%$ had negative $\mathrm{KOH}$ smear for the $\mathrm{KO}$ and $\mathrm{CC}$ groups, respectively. The difference, however, was again not statistically significant (Table 2).

Mild stinging of the involved ear canal was a common adverse reaction noted especially in the KO treatment. However, the intensity of the stinging was usually tolerable and was not strong enough to cause discontinuation of the treatment. There was only one patient who developed severe aural tenderness on the third day of treatment using $\mathrm{KO}$, which caused her to discontinue the use of the said medication. Other adverse effects were not encountered with either treatment.

\section{DISCUSSION}

With its persistence and annoying symptoms, otomycosis can be a challengingandfrustrating diseaseforboth patientand otolaryngologist. With the increasing cost of commercially available antifungal agents, finding locally-available alternative herbal treatments can greatly help patients, especially the less affluent.

A previous in vitro study of the antifungal activity of four medicinal plants versus clotrimazole in the treatment of otomycosis showed that kalachuchi (Plumeria acuminata Ait.) bark extract using methylethylketone as solvent at $100 \%$ concentration was comparable in efficacy with the standard clotrimazole solution in treating Aspergillus flavus and Aspergillus niger. ${ }^{12}$

This in vivo trial conducted to further determine the kalachuchi (Plumeria acuminata Ait.) bark extract's benefit as a topical antifungal agent against otomycosis showed no statistical significant difference between kalachuchi (Plumeria acuminata Ait.) bark extract ointment and clotrimazole cream $1 \%$ in terms of cure and complication rate. The cure rate for $\mathrm{KO}$ was $75 \%$ compared to $87.5 \%$ for CC. The results showed no significant difference between the two treatment groups based on chi-square analysis (Table 3). The failure rate for both treatment groups was relatively low (12.5\% and $25 \%$ ) for CC and KO, respectively (Table 3). This may be due to residual fungal growth in the difficult-to-access antero-inferior recess near the tympanic membrane which may not be reached by topical medications in the form of creams and ointments as well as improper application of the medication. Other preparations for kalachuchi extract may need to be explored for ease of application.

While this preliminary study may suggest that $\mathrm{KO}$ may be as effective as the CC as an antifungal agent for otomycosis, to compare two proportions testing for efficacy of either treatment, a sample size of at least 88 for each treatment group is needed to test for statistically significant difference, accounting for treatment success in each arm and drop out rates. Complication rates should also be documented to establish the safety of kalachuchi bark extract compared to standard treatment. A multicenter study is needed to develop kalachuchi extract as an important antifungal agent for otomycosis.

\section{Table 1. Baseline characteristics of Patients in the Kalachuchi bark extract \& Clotrimazole treatment groups}

\begin{tabular}{|c|c|c|c|c|c|c|c|}
\hline \multirow[b]{2}{*}{ CHARACTERISTICS } & \multirow{2}{*}{$\begin{array}{l}\text { TOTAL } \\
\text { NO. OF } \\
\text { PATIENTS }\end{array}$} & \multirow[b]{2}{*}{ FREQUENCY } & \multicolumn{2}{|c|}{ KALACHUCHI } & \multicolumn{2}{|c|}{ CLOTRIMAZOLE } & \multirow[b]{2}{*}{$\mathrm{p}$-value } \\
\hline & & & $\begin{array}{l}\text { N0.0F } \\
\text { PATIENTS }\end{array}$ & $\%$ & $\begin{array}{c}\text { N0. OF } \\
\text { PATIENTS }\end{array}$ & $\%$ & \\
\hline \multicolumn{8}{|l|}{ SIGNS \& SYMPTOMS } \\
\hline ITCHINESS & 10 & $62.5 \%$ & 5 & 62.5 & 5 & 62.5 & 0.50 \\
\hline EAR PAIN & 6 & $37.5 \%$ & 3 & 37.5 & 3 & 37.5 & 0.50 \\
\hline EAR DISCHARGE & 4 & $25 \%$ & 2 & 25 & 2 & 25 & 0.50 \\
\hline EAR FULLNESS & 12 & $75 \%$ & 6 & 75 & 6 & 75 & 0.50 \\
\hline HEARING IMPAIRMENT & 12 & $75 \%$ & 6 & 75 & 6 & 75 & 0.50 \\
\hline \multicolumn{8}{|l|}{ OTOSCOPIC FINDINGS } \\
\hline ERYTHEMATOUS EAC & 8 & $50 \%$ & 4 & 50 & 4 & 50 & 0.50 \\
\hline HYPHAL ELEMENTS & 16 & $100 \%$ & 8 & 100 & 8 & 100 & 0.50 \\
\hline EAR DISCHARGE & 5 & $34 \%$ & 3 & 37.5 & 2 & 25 & 0.29 \\
\hline
\end{tabular}

Critical values: 
Table 2. Comparison of the response after 7 days of treatment between Kalachuchi bark extract \& Clotrimazole

\begin{tabular}{|c|c|c|c|c|c|c|c|c|c|c|}
\hline \multirow[b]{3}{*}{ CHARACTERISTICS } & \multicolumn{5}{|c|}{ AFTER 7 DAYS OF TREATMENT } & \multicolumn{5}{|c|}{ AFTER 14 DAYS OF TREATMENT } \\
\hline & \multicolumn{2}{|c|}{ KALACHUCHI } & \multicolumn{2}{|c|}{ CLOTRIMAZOLE } & \multirow[b]{2}{*}{ p-value } & \multicolumn{2}{|c|}{ KALACHUCHI } & \multicolumn{2}{|c|}{ CLOTRIMAZOLE } & \multirow[b]{2}{*}{ p-value } \\
\hline & $\begin{array}{c}\text { NO.OF } \\
\text { PATIENTS }\end{array}$ & $\%$ & $\begin{array}{c}\text { NO.OF } \\
\text { PATIENTS }\end{array}$ & $\%$ & & $\begin{array}{c}\text { NO. OF } \\
\text { PATIENTS }\end{array}$ & $\%$ & $\begin{array}{c}\text { NO.OF } \\
\text { PATIENTS }\end{array}$ & $\%$ & \\
\hline \multicolumn{11}{|l|}{ SIGNS \& SYMPTOMS } \\
\hline ITCHINESS & 3 & 37.5 & 2 & 25 & 0.29 & 2 & 25 & 2 & 25 & 0.50 \\
\hline EAR PAIN & 2 & 25 & 1 & 12.5 & 0.26 & 0 & 0 & 1 & 12.5 & 0.15 \\
\hline EAR DISCHARGE & 1 & 12.5 & 2 & 25 & 0.26 & 0 & 0 & 0 & 0 & - \\
\hline EAR FULLNESS & 5 & 62.5 & 3 & 37.5 & 0.16 & 2 & 25 & 2 & 25 & 0.50 \\
\hline HEARING IMPAIRMENT & 5 & 62.5 & 3 & 37.5 & 0.16 & 2 & 25 & 2 & 25 & 0.50 \\
\hline NOSYMPTOMS & 2 & 25 & 3 & 37.5 & 0.29 & 5 & 62.5 & 5 & 62.5 & 0.50 \\
\hline \multicolumn{11}{|l|}{ OTOSCOPIC FINDINGS } \\
\hline ERYTHEMATOUS EAC & 2 & 25 & 2 & 25 & 0.50 & 0 & 0 & 0 & 0 & - \\
\hline HYPHAL ELEMENTS & 5 & 62.5 & 2 & 25 & 0.07 & 1 & 12.5 & 1 & 12.5 & 0.50 \\
\hline EAR DISCHARGE & 1 & 12.5 & 2 & 25 & 0.26 & 1 & 12.5 & 1 & 12.5 & 0.50 \\
\hline NORMAL FINDINGS & 3 & 37.5 & 5 & 62.5 & 0.16 & 7 & 87.5 & 7 & 87.5 & 0.50 \\
\hline \multicolumn{11}{|l|}{ KOH SMEAR } \\
\hline$(+)$ & 7 & 87.5 & 4 & 50 & 0.11 & 2 & 25 & 1 & 12.5 & 0.52 \\
\hline$(-)$ & 1 & 12.5 & 4 & 50 & & 6 & 75 & 7 & 87.5 & \\
\hline
\end{tabular}

Critical values:

$p$-value $\leq 0.05$ significant difference

$p$-value $>0.05$ no significant difference

Table 3. Comparison of the cure rate between the Kalachuchi bark extract \&

\section{Clotrimazole treatment}

\begin{tabular}{|l|c|c|c|c|}
\multirow{2}{*}{ TREATMENT } & \multicolumn{2}{|c|}{ CURE } & \multicolumn{2}{c|}{ FAILURE } \\
\cline { 2 - 5 } & $\begin{array}{c}\text { N0. OF } \\
\text { PATIENTS }\end{array}$ & $\%$ & $\begin{array}{c}\text { N0. OF } \\
\text { PATIENTS }\end{array}$ & $\%$ \\
KALACHUCHI & 6 & 75 & 2 & 25 \\
CLOTRIMAZOLE & 7 & 87.5 & 1 & 12.5 \\
p-value & 0.52 & & & \\
\hline
\end{tabular}

Critical values:

$p$-value $\leq 0.05$ significant difference

$p$-value $>0.05$ no significant difference

\section{ACKNOWLEDGEMENT}

The authors wish to thank Dr. Jose Mari Fermin, Medical Director of Western Visayas Medical Center and its Research Committee for their financial support. Mrs. Monalisa Avanceňa and staff of the Western Visayas Medical Center Pathology Department for their help with microbiologic examinations. Dr. Gerard Penecilla of the West Visayas State University Microbiology Laboratory for his help and guidance during the process of kalachuchi bark extraction and preparation of kalachuch ointment. Prof. Isabel Blancia for her expertise, time, and service in statistical analysis and the residents of the Department of Otorhinolaryngology Head and Neck Surgery, Western Visayas Medical Center for their support.

\section{REFERENCES}

1. Geaney GP. Tropical otomycosis. J Laryngol Otol. 1967; 81: 987-97.

2. Lakshmipati G, Murti RB. Otomycosis. J Indian Med Assoc. 1960; 34:439-41.

3. Paulose KO, Al Khalifa S, Shenoy P, Sharma RK. Mycotic infection of the ear (otomycosis): Aprospective study. J Laryngol Otol. 1989; 103:30.

4. Than KM, Naing KS, Min M. Otomycosis in Burma and its treatment. Am JTrop Med Hyg. 1980; 29:520.

5. Mathur MD. Otomycosis: A clinicomycologic study. ENT J. $2000 ; 79: 606-9$.

6. Ballantine J, Groves J. Scott-Brown's Diseases of the Ears, Nose and Throat. Boston: Butterworths, 4th ed., 93-114.

7. Patow CA. Fungi as a cause of otitis. J Am Med Assoc. $1995 ; 273$ (1):25.

8. Ologe FE, Nwabuisi C. Treatment outcome of otomycosis in llorin, Nigeria. West Afr J Med. 2002; 21(1):34-36

9. Kwok P, Hawke, M. Clotrimazole powder in the treatment of otomycosis. J Otolaryngol. 1987; 16:398.

10. Stern JC, Shah MK, Lucente FE. In vivo effectiveness of 13 agents in otomycosis and review of the literature. Laryngoscope. 1988; 98:1173.

11. Penecilla G, Magno C, de Castro J. et al. Production and testing of natural products for antimicrobial and antifungal action. West Visayas State University College of Arts and Sciences Research Journal. 2001; 2 (1):10-20.

12. Villanueva JM, Arugay MAV, Ramos RZH. In vitro antimycotic activity of four medicinal plants versus Clotrimazole in the treatment of otomycosis: a preliminary study. Philipp J Otolaryngo Head Neck Surg 2008; 23(1): 5-8.

13. Plumeria acuminata Ait. Republic of the Philippines, Department of Agriculture, Bureau of Plant Industry. 